\title{
SOME RESULTS FROM A LINEAR-VISCOUS MODEL OF THE ARGTIG ICE COVER
}

\author{
By W. D. Hibler III and W. B. Tucker III \\ (U.S. Army Cold Regions Research and Engineering Laboratory, Hanover, New \\ Hampshire 03755 , U.S.A.)
}

\begin{abstract}
In order to assess the effect of non-local stress transferral through the ice cover empirically, a linear viscous model (employing both bulk and shear viscosities) is used to predict drift-rates for one Soviet and two U.S. drifting stations over the time period May 1962 to April 1964. The predictions, based on available atmospheric pressure and ocean-current data, are compared to free-drift results and to observed values. The empirical viscosity values giving the best fit to observations show a pronounced seasonal variation that correlates well with the growth rate of thin ice. Drift predictions, especially long-term net drift results, show drift magnitudes and turning angles to be simulated significantly better by a viscous model than by a free-drift model. The effects of steady currents are shown to be small for velocities averaged over days but significant for averages over years.
\end{abstract}

RÉsumÉ. Quelques resultats d'un modèle visqueux linéaire du Pack arctique. En vue d'appréhender empiriquement l'effet du transfert d'efforts d'origine non locale sur le Pack, on a utilisé un modèle visqueux linéaire limité dans le temps, pour prévoir le taux de transport de neige par le vent constaté dans une station russe et deux stations U.S. pour la période Mai 1962 à Avril r 964 . Les prévisions, basées sur les données disponibles concernant la pression atmosphérique et les courants océaniques, sont comparées aux résultats que donnerait un transport libre et aux valeurs observées. Les valeurs empiriques de la viscosité qui s'ajustent le mieux aux observations montrent une variation saisonnière prononcée qui s'accorde bien avec le taux de croissance de la glace mince. Les prévisions de transport, surtout les résultats de l'apport net à long terme montrent que les grandeurs et la direction des transports sont mieux estimés par le modèle visqueux que par un modèle de transport libre. On montre que les effets de courants permanents sont faibles sur des moyennes de vitesses calculées à partir de quelques jours, mais significatifs si l'on établit ces moyennes à l'échelle de quelques années.

Zusammenfassung. Einige Ergebnisse eines linear-viskosen Modells der arktischen Eisdecke. Zur empirischen Erfassung des Einflusses der Übertragung ortsfremder. Spannungen durch die Eisdecke wird ein linearviskoses Modell, das sowohl die Gesamt- wie die Scherviskosität verwendet herangezogen, das die Driftraten einer russischen und zweier US-amerikanischer Driftstationen im Zeitraum Mai I962 bis April I964 vorausbestimmen lässt. Die Vorhersagen, die sich auf verfügbare Daten über den Luftdruck und die Meeresströmung stützen, werden mit Berechnungen der freien Drift und mit beobachteten Werten verglichen. Die empirischen Werte der Viskosität, die am besten zu den Beobachtungen passen, zeigen einen ausgesprochenen jahreszeitlichen Gang, der in enger Korrelation zur Wachstumsrate dünnen Eises steht. DriftVorhersagen, besonders Ergebnisse für die langfristige Netto-Drift, zeigen, dass die Driftstrecken und Drehwinkel durch ein viskoses Modell wesentlich besser simuliert werden als durch ein Modell der freien Drift. Was die Reaktion auf Strömungswirkungen betrifft, so erweisen sich die Einflüsse stetiger Strömungen auf die Mittelwerte der Geschwindigkeit über einige Tage als gering, jedoch als beträchtlich auf Mittelwerte über Jahre.

\section{INTRODUCTION}

To model pack-ice motions properly requires some constitutive law describing the interaction of an area of pack ice with the surrounding ice. In complete simulation models in which ice thickness characteristics are coupled to ice strengths, plastic or non-linear viscous rheologies appear to hold the best promise for proper modelling of ice stress (e.g. Coon and others, 1974 , Hibler, in press), especially near boundaries. However, as a first step in isolating the effect of ice stress on drift, simple linear viscous calculations with bulk and shear viscosities varying in a seasonal manner can yield considerable insight. Moreover, for periods of several days or more, in a reasonably homogeneous region far from shore, stochastic arguments (Hibler, 1977) suggest that a viscous law with the inclusion of both a bulk and shear viscosity may be a reasonable estimate of a time-averaged plastic rheology. It is also noteworthy that a model with both bulk and shear viscosity can behave quite differently from the Newtonian viscous models (with only a shear viscosity) used by Campbell (r965) and Doronin (1970). 
In order to assess the effects of ice stress in a relatively simple manner, a number of linear viscous calculations with various types of boundary conditions were carried out. These calculations provide a feeling for the sensitivity of drift to the various forcing fields and boundary effects, and give estimates of approximate strengths needed in both viscous and plastic models. A more detailed description of these calculations is available (Hibler and Tucker, 1977). This paper presents some of the more important results from this study pertaining to ice drift far from shore. In particular we discuss here a series of calculations made with periodic boundary conditions and different viscosities. The calculated drift-rates are then compared with observations over a two-year period. The observed drift-rates were obtained from records of one Russian and two U.S. drifting stations, spanning the time period May 1962 to April 1964 . To drive the model, daily atmospheric pressure data compiled by the National Center for Atmospheric Research (NCAR) and steady-current data reported by Coachman and Aagaard (1974) were used. In the calculations the viscosity parameter is allowed to vary with time but not spatially. Considerable effort is devoted to examining the empirical seasonally-varying viscosity giving the best fit to observations in order to assess the effects of ice stress on drift-rates. In addition seasonally varying viscosity predictions, both with and without currents, are compared to free-drift results and observations. These comparisons help identify the effect of the increased winter ice interaction on the drift and deformation.

\section{LINEAR-VISCOUS DRIFT MODEL}

For drift calculations, we make use of a linear drift theory similar to that used by Hibler (1974). In this model, steady-state equilibrium drift is considered with the following governing equation:

$$
-m f \mathbf{k} \times \mathbf{u}+\boldsymbol{\tau}_{\mathrm{w}}+\boldsymbol{\tau}_{\mathbf{a}}+\mathbf{F}+\mathbf{G}+\mathbf{T}=0,
$$

where $\mathbf{u}$ is the ice velocity, $f$ the Coriolis parameter, $\mathbf{k}$ a unit vector normal to the $x, y$ plane, $m$ the ice mass per unit area, $\mathbf{F}$ the force due to variation in internal ice stress, $\boldsymbol{\tau}_{\mathrm{w}}$ and $\boldsymbol{\tau}_{\mathrm{a}}$ the water and air stresses on the ice, and $\mathbf{G}$ and $\mathbf{T}$ the effect of long term geostrophic currents and ocean tilt on the ice motion. The components of current and ice stresses are given by a modified Ekman layer theory (see, for example, Rothrock, 1975).

$$
\left.\begin{array}{rl}
\tau_{\mathrm{a} x} & =B\left(L_{\mathrm{g}} \cos \phi-V_{\mathrm{g}} \sin \phi\right), \\
\tau_{\mathrm{a} y} & =B\left(L_{\mathrm{g}} \sin \phi+V_{\mathrm{g}} \cos \phi\right), \\
G_{x}+\tau_{\mathrm{w} x} & =D\left(-\left(u_{x}-V_{\mathrm{w}}\right) \cos \theta+\left(u_{y}-V_{\mathrm{w}}\right) \sin \theta_{\}},\right. \\
G_{y}+\tau_{\mathrm{w} y} & =-D\left\{\left(u_{x}-L_{\mathrm{w}}\right) \sin \theta+\left(u_{y}-V_{\mathrm{w}}\right) \cos \theta_{j},\right.
\end{array}\right\}
$$

where $\phi$ and $\theta$ are Ekman angles in the air and water respectively, $U_{\mathrm{g}}$ and $V_{\mathrm{g}}$ are the $x$ and $y$ components of the geostrophic wind, $V_{\mathrm{w}}$ and $V_{\mathrm{w}}$ are the $x$ and $y$ components of the geostrophic ocean flow beneath the Ekman layer, and $B$ and $D$ are constant wind and water stress parameters. In Equation (2), the $\mathbf{G}$ components are those components linear in $I_{\mathrm{w}}$ and $V_{\mathrm{w}}$. In the case when $\mathbf{G}$ is neglected, the sea ice is effectively considered to be moving across a stagnant ocean. The geostrophic current flow is computed by $\mathbf{U}_{\mathbf{w}}=g f^{-1} \mathbf{k} \times \boldsymbol{\nabla} H$ where $g$ is the gravitational acceleration, and $H$ is the sea-surface height. The tilt component is given by $\mathbf{T}=-m g \boldsymbol{\nabla} H$ and the geostrophic wind is related to the surface atmospheric pressure $P$ by $\mathbf{U}_{\mathrm{g}}=\left(\rho_{\mathrm{a}} f\right)^{-1} \mathbf{k} \times \boldsymbol{\nabla} P$ with $\rho_{\mathrm{a}}$ the density of air.

The force $\mathbf{F}$ due to internal ice stress is obtained from the viscous constitutive law proposed by Glen (1970) relating ice stress and strain-rates in the ice

$$
\sigma_{i j}=2 \eta \dot{\epsilon}_{i j}+(\zeta-\eta) \dot{\epsilon}_{k k} \delta_{i j}
$$

so that

$$
F_{i}=\frac{\hat{c}}{\hat{\imath} x_{j}} \sigma_{i j}=\eta \boldsymbol{\nabla}^{2} u_{i}+\zeta \boldsymbol{\nabla}_{i}\left(\boldsymbol{\nabla}_{k} u_{k}\right)
$$


where $\eta$ and $\zeta$ are the shear and bulk viscosities characterizing the ice cover on the geophysical scale. Substituting the various stresses into Equation (I), a system of two coupled second-order linear partial differential equations are obtained for the drift rates $u_{x}(x, y)$ and $u_{y}(x, y)$. For our purposes here, these equations are solved in the infinite boundary case using a Green function generated by transforms. Following Hibler (1974), the procedure is to Fourier transform the coupled equations and solve for the transformed values of $u_{x}$ and $u_{y}$. These transformed values are then inverted yielding equations of the form

$$
u_{i}(\mathbf{x})=\int G_{i j}\left(\mathbf{x}-\mathbf{x}^{\prime}\right) S_{j}\left(\mathbf{x}^{\prime}\right) \mathrm{d} \mathbf{x}^{\prime},
$$

where $S_{j}$ is the $j$ th component of the external stresses due to wind, tilt, and geostrophic currents. Using an input grid of stresses due to wind, currents, and tilt, the convolutions in Equation (4) are approximated by two-dimensional discrete sums which yield periodic rather than infinite boundaries.

The principal justification for the periodic boundary solution is that the response function $G_{i j}(\mathbf{x})$ falls off to small values for large $\mathbf{x}$ at a rate which decreases for increasing viscosities. For example, the response function for drift-rate magnitude due to $x$ stress components for viscosity parameters of $\eta=\zeta=4 \times 10^{11} \mathrm{~kg} / \mathrm{s}$, falls off to less than $15 \%$ of the maximum at a distance of $875 \mathrm{~km}$. Consequently boundary effects on predicted drift-rates far from shore should be minimal.

\section{INPUT DATA}

The basic input fields for predicting drift and deformation of sea ice are the atmospheric pressure and the dynamic height of the sea surface. For computational purposes all input fields were reduced to a $16 \times 16$ square grid of $25^{\circ} \mathrm{km}$ mesh. This spacing was thought to be reasonable taking into consideration the accuracy of the input pressure data and the areal coverage, and in the interest of computer time.

The grid, shown in Figure $\mathrm{I}$, is oriented with the $x$ axis parallel to long. $150^{\circ} \mathrm{W}$. and the $y$ axis parallel to long. $60^{\circ} \mathrm{W}$. In this configuration the geographic North Pole conveniently has the grid coordinates $(\mathrm{I} I, 6)$. This orientation also has the $y$ axis roughly parallel to the north coast of Alaska.

For determination of geostrophic winds, sea-level barometric pressure data were obtained from the National Center for Atmospheric Research. The data were recorded at $12 \mathrm{~h}$ intervals and data points were located every five degrees of latitude and longitude. The pressure data were averaged over $8 \mathrm{~d}$ intervals and then sampled at $4 \mathrm{~d}$ intervals. The smoothed data were converted to the standard $16 \times 16$ grid using the cubic spline gridding procedure discussed by Davis and Kontis (1970) and then differentiated using discrete transforms to obtain geostrophic wind estimates. As a check on the accuracy of the pressure data and on the gridding procedure, comparisons were made between similarly averaged Arlis II observations and a pressure interpolated from the gridded data corresponding to the position of Arlis II. Good agreement was obtained except during times of rapid pressure fluctuations.

For the oceanic dynamic height, average values obtained by Coachman and Aagaard (1974) were used. Since in this case only one fixed set of data is used it was convenient to prepare a data grid by hand using a visual overlay of the dynamic-height contour map.

For comparisons with model predictions we made use of position measurements of three contemporaneous drifting stations T-3, Arlis II, and NP-Io over a 2 year period from May I962 to April I964. The original and final positions of the stations are shown in Figure 8. These data were averaged over $8 \mathrm{~d}$ intervals to suppress rather large measurement errors, and then resampled every $4 \mathrm{~d}$. (This is the same type of smoothing as applied to the time series for the gridded geostrophic wind). 


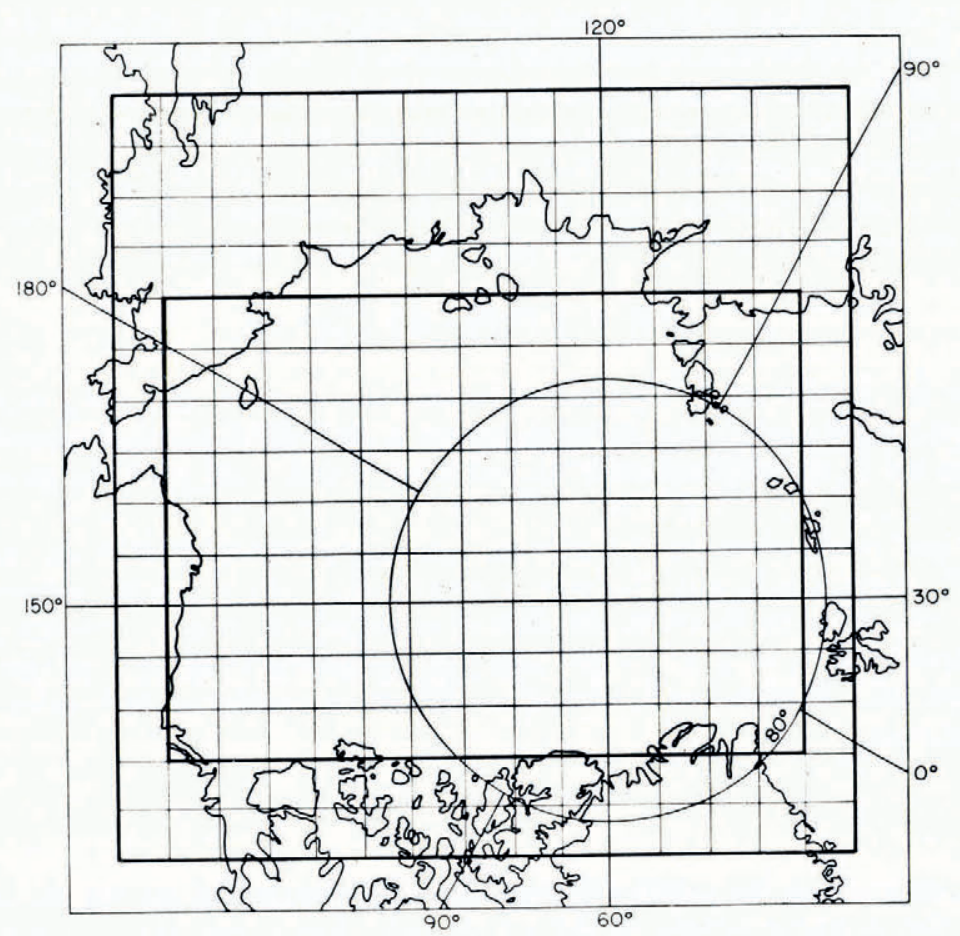

Fig. I. Square mesh grid used for numerical calculations.

\section{RESUlts}

\section{Empirical determination of seasonal viscosity variation}

In order to estimate temporal variations for the viscosity parameters in the model, an empirical fit between the observed and predicted drift of the three ice stations over a two-year period was carried out. For this purpose predicted $x$ and $y$ drift-rates for each station were generated every four days over a period of $760 \mathrm{~d}$ using the eight different values of viscosity listed in Table I. For this fit as well as for subsequent comparisons, the bulk and shear viscosities were taken to be equal. In general, to predict a drift-rate for a given drifting station, the velocity vector is centered on the station location at the beginning of a 4 -day interval by interpolating drift rates from the three nearest grid points. Consequently, the predicted driftrates from currents and tilt will vary in time as the position of the stations changes. However, as this variation was found to be small compared with variations in day-to-day geostrophic winds, the geostrophic current and tilt components were neglected in the calculation of the short-term drift-rates used to estimate the best-fit viscosity.

The standard values of the numerical parameters used in the calculations are shown in Table I. These values are similar to those used by Rothrock (1975). For each viscosity, we

TABle I. Numerical PARAMETERS USED IN DRIFT PREDICTION

$$
\begin{array}{lc}
B=0.0146 \mathrm{~kg} \mathrm{~s}^{-1} \mathrm{~m}^{2} & \eta, \zeta=0.45 \times 10^{10} \mathrm{~kg} \mathrm{~s}^{-1} \\
D=0.59 \mathrm{~kg} \mathrm{~s}^{-1} \mathrm{~m}^{2} & 0.94 \\
f=\mathrm{I} .46 \times \mathrm{IO}^{-4} \mathrm{~s}^{-1} & 2.0 \\
g=9.832 \mathrm{~m} \mathrm{~s}^{-2} & 4.2 \\
\phi=\theta=30^{\circ} & 9.0 \\
m=3.0 \times 1 \mathrm{~kg} \mathrm{~m}^{-2} & 19.0 \\
\rho_{\mathrm{a}}=1.3 \mathrm{~kg} \mathrm{~m}^{-3} & 85.0
\end{array}
$$



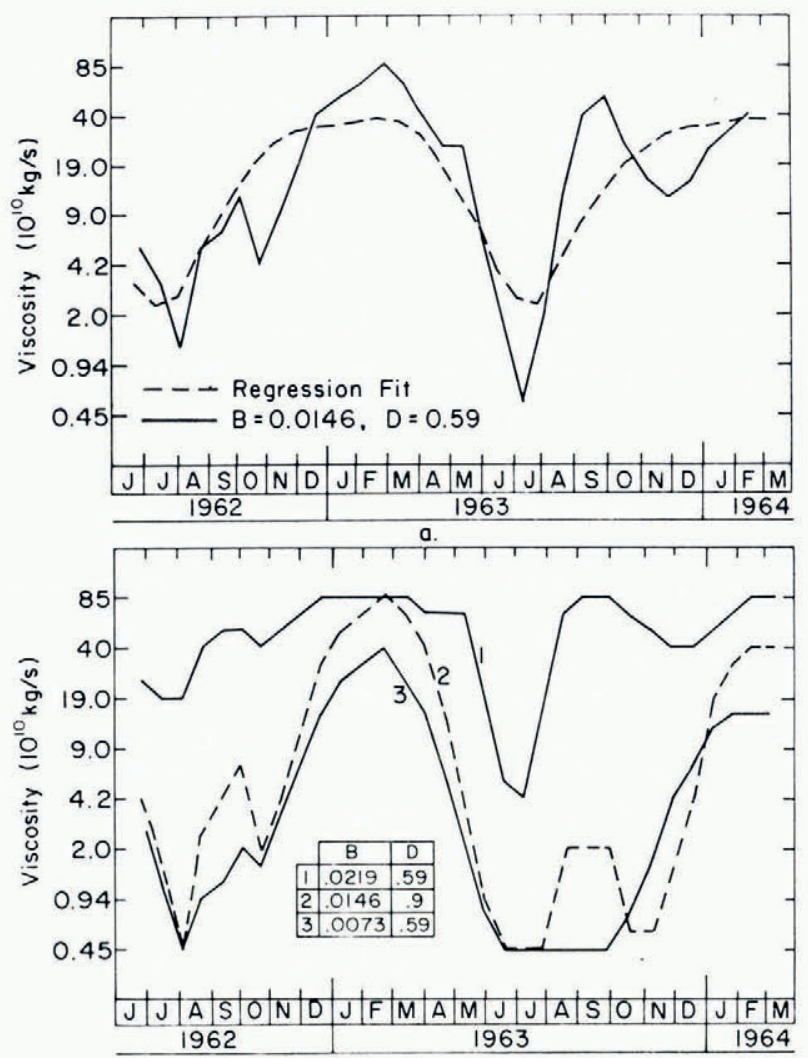

b.

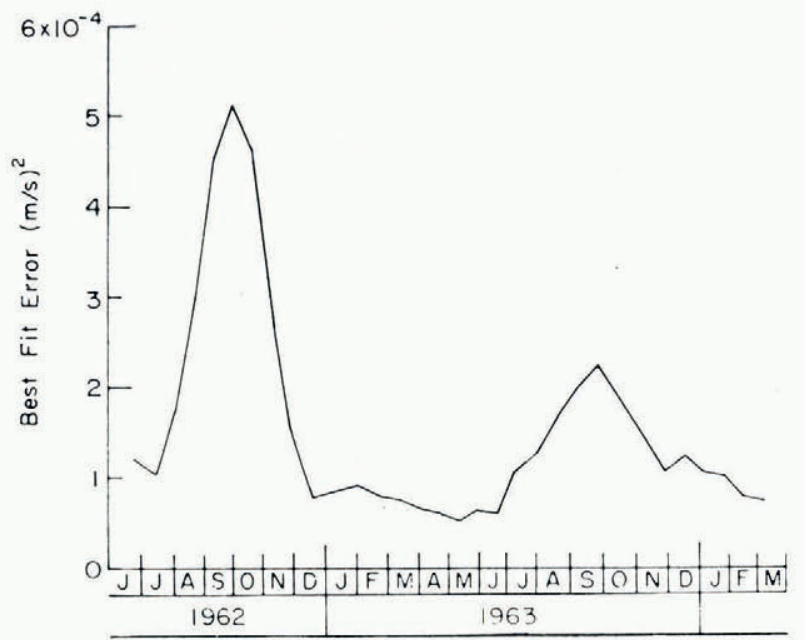

Fig. 2.

a. Viscosity values (solid line) giving the best fit between predicted and observed drift-rates for standard values of the wind and water stress parameters $B$ and $D$. The dashed line is a regression fit of viscosity upon the $60 d$ averaged growth rate of $50 \mathrm{~cm}$-thick ice (see Equation (5)).

b. The effect on the best-fit viscosity of increasing (curve 1 ) and decreasing (curve 3) the wind stress coefficient and increasing the water stress coefficient (curve 2).

c. Mean square error between predicted and observed drift-rates for the best-fit viscosity. 
calculated the sum of squared differences between the predicted and observed ice velocity components of the centroid of the three drifting stations. The best-fit viscosity was obtained by minimizing the sum of squares over running $60 \mathrm{~d}$ intervals.

The viscosity results are shown in Figure 2. Part b of this figure shows the effect on the best-fit viscosity of modifying the wind and water stress coefficients. The most salient characteristic of this figure is the seasonal variation of the best-fit viscosity. Comparison of the best-fit viscosity (standard case) with $60 \mathrm{~d}$ smoothed growth rates of $50 \mathrm{~cm}$ ice (taken from Thorndike and others, 1975) shows a good correlation. The best correlation (o.8o, significant at the $0.01 \%$ level) occurred with zero lag time (that is, when the viscosity does not lead or lag behind the growth rate). The regression equation for the best-fit viscosity is given by

$$
\ln (\eta)=\ln (\zeta)=0.92\langle G\rangle+24 \cdot 73,
$$

where $\langle G\rangle$ is the $60 \mathrm{~d}$ averaged growth rate of $50 \mathrm{~cm}$ thick ice in units of $\mathrm{cm} / \mathrm{d}$ and $\zeta$ has units of $\mathrm{kg} \mathrm{s}^{-1}$. The dashed line in part a of Figure 2 shows the viscosity generated by the regression equation. Since $\langle G\rangle$ varies in a seasonal manner, Equation (5) effectively yields a "seasonal" viscosity. The best-fit viscosities for different wind and water stress parameters are similar in form to the standard case with the curves being shifted up for higher wind stress (or lower water stress) and down for lower wind stress.

Figure $2 \mathrm{c}$ shows the error for the best-fit viscosity. This error tends to be of the order of I or $2 \mathrm{~cm} \mathrm{~s}^{-1}$ ( $\approx \mathrm{I}$ to 2 nautical miles per day). Interestingly enough, the error tends to get very large around September, when an oscillation in the best-fit viscosity can be seen in Figure 2a. Since September more or less marks the end of the summer melt season, this effect may indicate that certain aspects of the model assumptions are breaking down then. One possibility is that the ocean current structure has become modified due to large amounts of open water.

The dominant effect, which seems to account for much of the seasonal viscosity variation exhibited in Figure 2, is a decrease in drift-rate amplitude as the viscosity is increased. This is illustrated in Figure 3, where we show the observed and predicted three-station average velocity for low and high viscosities of $1.0 \times 10^{10} \mathrm{~kg} \mathrm{~s}^{-1}$ and $4.0 \times 10^{11} \mathrm{~kg} \mathrm{~s}^{-1}$. Physically the increase in viscosity increases the capability of the ice pack to transmit stress. When this occurs the drift tends to be driven by the average wind over a large region rather than the local wind. However, it should be noted here that the linear response function (Equation (4)) for predicting the ice drift is not symmetric. Consequently, increasing the ice interaction is not the same as reducing the wind stress. In particular, increasing the viscosity can cause a counterclockwise turning of the drift direction of up to $20^{\circ}$. This characteristic will be illustrated later.

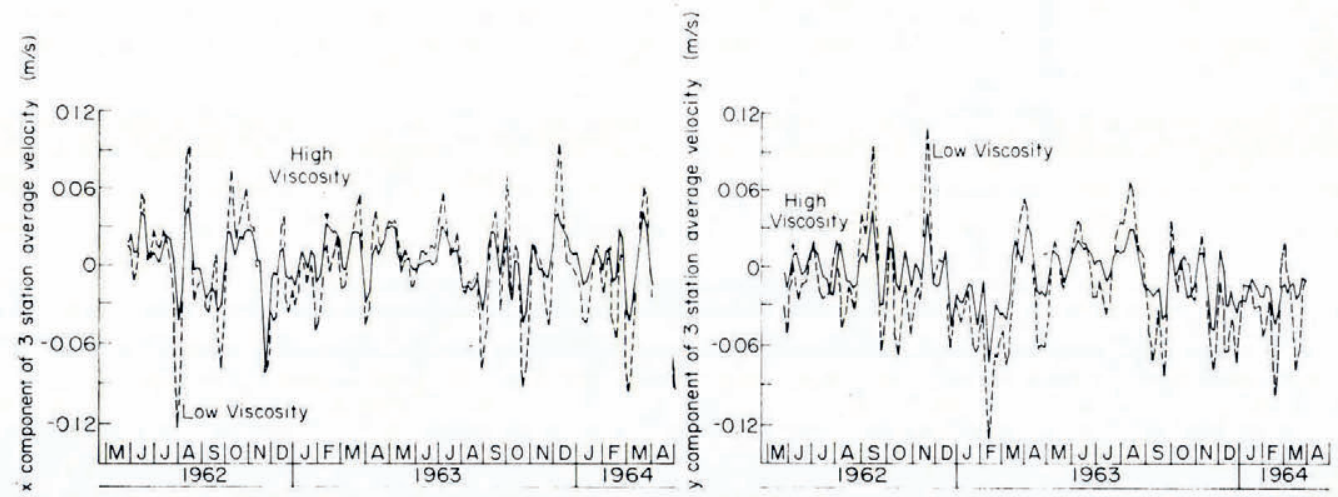

Fig. 3. Average drift-rate of the three drifting stations. The curves show predicted drift-rates using constant viscosities of $1 \times 10^{10} \mathrm{~kg} / \mathrm{s}$ (low viscosity) and $4.0 \times 10^{11} \mathrm{~kg} / \mathrm{s}$ (high viscosity). 

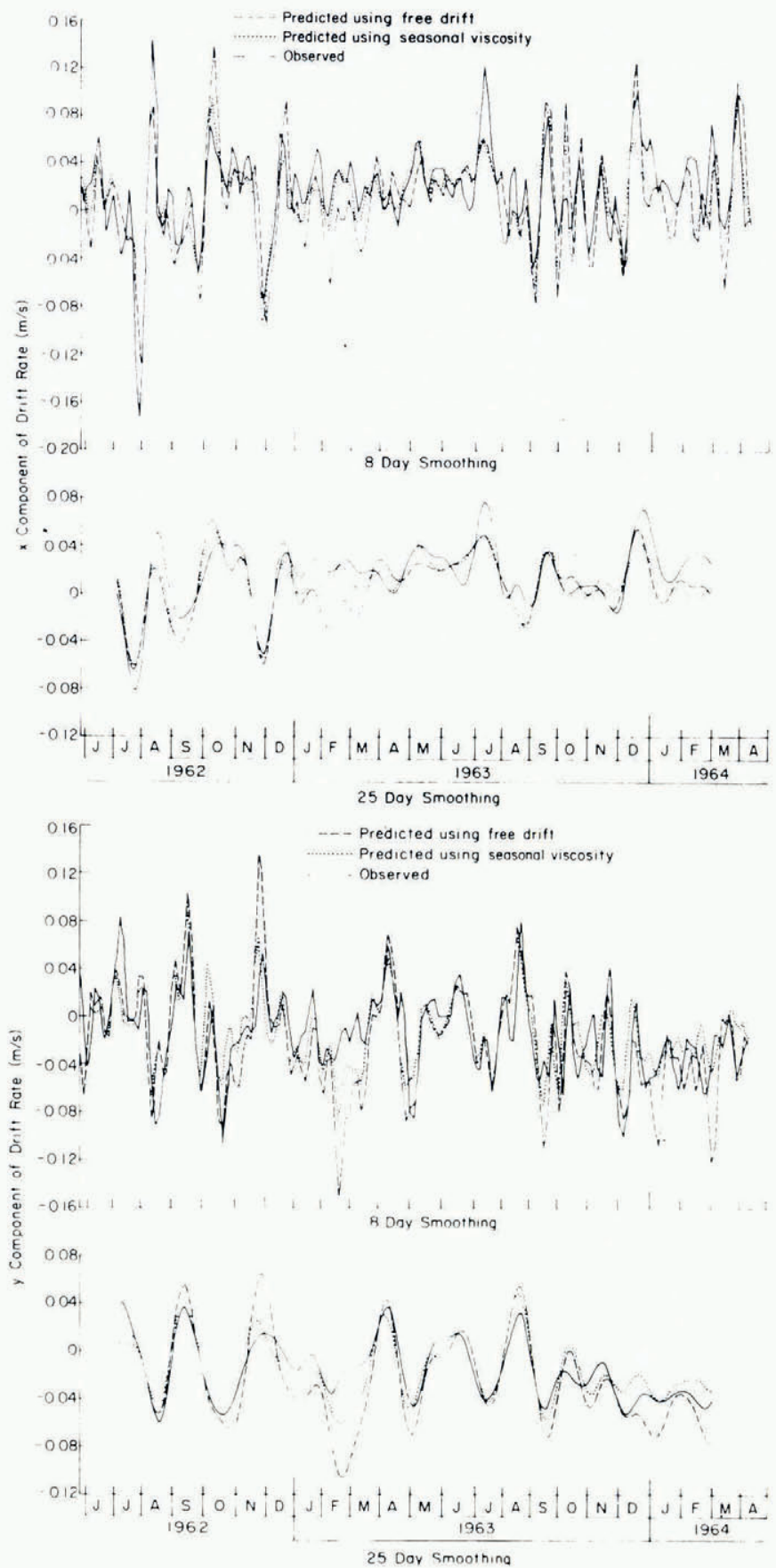

Fig. 4. Predicted and observed drift-rates of $\mathcal{N} P$-Io for seasonally varying viscosity and free drift for $8 d$ and $2.5 d$ smoothing. 


\section{A comparison of seasonal viscosity and free-drift results}

In the previous section the best fit viscosity was shown to have a pronounced seasonal variation indicating an increased stress transfer through the pack ice in winter. To help assess the character and magnitude of this effect on the drift-rates it is useful to compare the seasonal viscosity predictions with both the free-drift predictions and observed results. For this comparison, drift predictions were made using Equation (5) to generate seasonal viscosities. The free-drift case was estimated by using a constant low viscosity of $\mathrm{I} \times \mathrm{IO}^{10} \mathrm{~kg} \mathrm{~s}^{-1}$. All predictions and observed data were digitally filtered to assess the predictability of the different time-scale components of the drift-rate for the 2 year period. Figure 4 shows $8 \mathrm{~d}$ and $25 \mathrm{~d}$ smoothed ice velocity components for the ice station NP-Io. While neither the free-drift or seasonal-viscosity prediction is obviously superior, the comparisons show that the free-drift case tends to predict excessive velocity during the winter months. A more quantitative comparison of the free-drift and seasonal-viscosity predictions for NP-Io is given in Table II. This table presents the root-mean-square (r.m.s.) differences between these predictions and the observed drift rates (normalized to the observed standard deviation). For a more direct measure of the amplitude of the variance of the predictions, Table III gives the ratio of the predicted to observed variances.

TABLE II. R.M.S. DIFFERENCÉS BETWEEN PREDICTED AND OBSERVED NP-IO DRIFT-RATES (Normalized to observed standard deviations)

\begin{tabular}{|c|c|c|c|c|}
\hline \multirow[b]{2}{*}{ Filter } & \multicolumn{2}{|c|}{ Seasonal viscosity } & \multicolumn{2}{|c|}{ Free drift } \\
\hline & $x$ & $y$ & $x$ & $y$ \\
\hline 8 day low-pass & 0.45 & 0.65 & 0.60 & 1.00 \\
\hline 25 day low-pass & 0.32 & 0.39 & $0.5^{1}$ & 0.90 \\
\hline 25 day high-pass & 0.66 & 1.00 & 0.80 & 1. 13 \\
\hline
\end{tabular}

These tables show that the seasonal viscosity is superior to the free drift. The normalized r.m.s. differences are consistently lower, for both $x$ and $y$ components, for the seasonal viscosity predictions. However, the variance ratios indicate that the viscous predictions appear to be overdamped at high frequencies. The free-drift values on the other hand have a greater amplitude but, as Figure 3 and Table II indicate, it is not always the correct amplitude.

The cumulative drift of the three stations illustrates somewhat more graphically the effect of the ice interaction on the drift. Figure 5 shows cumulative drift plotted every $60 \mathrm{~d}$ for the seasonal-viscosity and free-drift cases. The variable-viscosity model gives better magnitudes and directions of displacement than does the free-drift model. This turning-angle effect is particularly important since it is an effect that cannot be obtained by simply reducing the forcing field. Consequently, although the addition of an ad hoc seasonally varying free-drift parameter (which controls the magnitude of the response to the forcing fields) might improve the free-drift magnitudes, it would not predict correct directions.

TABLE III. VARIANCE OF PREDICTED NP-IO DRIFT-RATES (Normalized to observed variances)

\begin{tabular}{cccccc} 
& \multicolumn{2}{c}{ Seasonal viscosity } & & \multicolumn{2}{c}{ Free drift } \\
\cline { 2 - 5 } Filter & $x$ & $y$ & & $x$ & $y$ \\
8 day low-pass & 0.71 & 0.79 & & 0.92 & 1.67 \\
25 day low-pass & 0.77 & 0.95 & & 0.90 & 2.22 \\
25 day high-pass & 0.70 & 0.58 & & 1.22 & 0.98
\end{tabular}




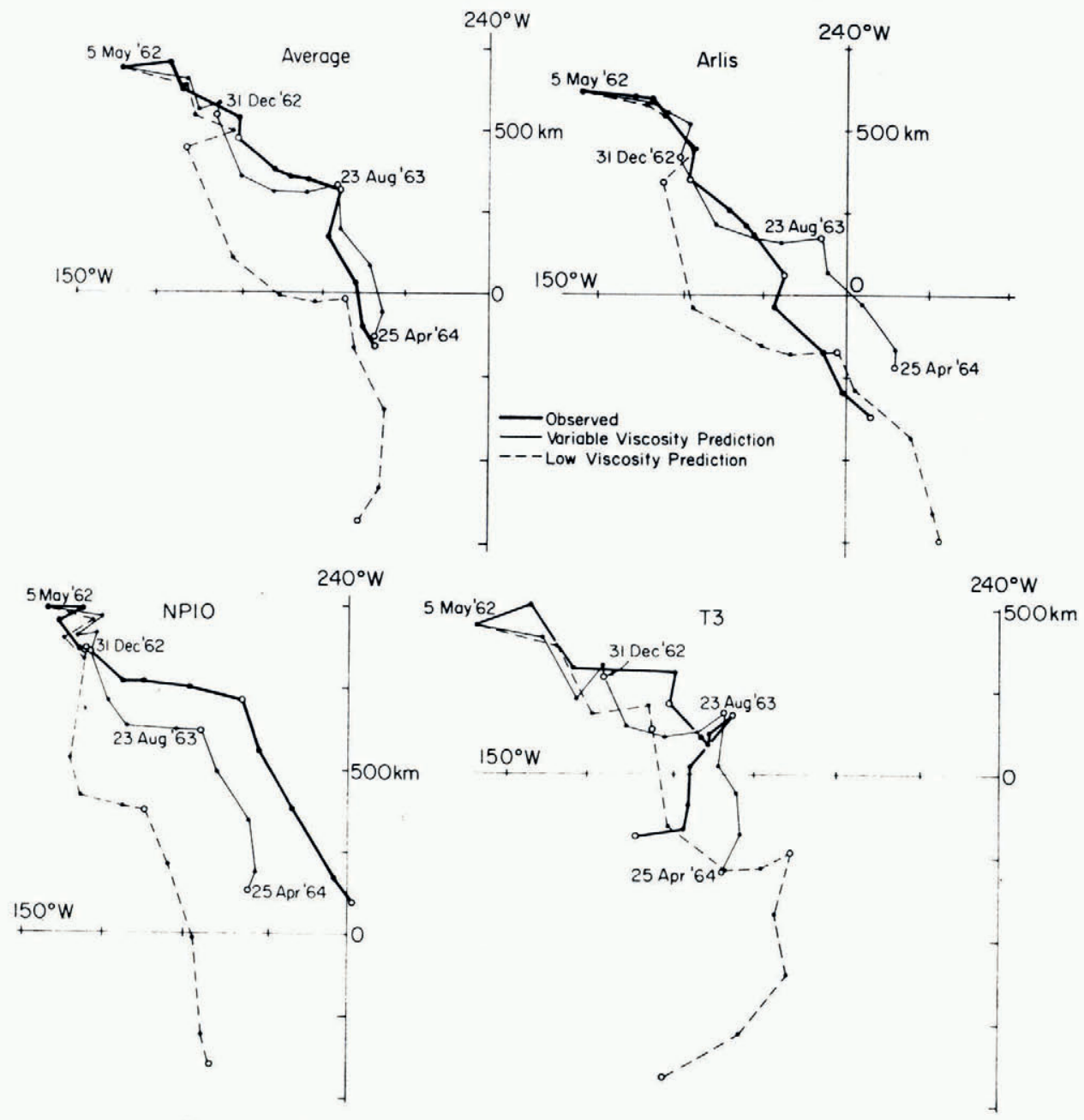

Fig. 5. Predicted and observed cumulative 6o d drift for each drifting station.

\section{Sensitivity of drift predictions to currents}

Since the average geostrophic currents are relatively small compared to the winds, it would be expected that currents would not significantly affect short-term velocity predictions. That this is indeed the case is illustrated in Figure 6.

In examining cumulative drift over time periods of several years, however, significant differences occur if currents and tilt are neglected. This is because the current effects, while small, are relatively constant. The wind effects, on the other hand, fluctuate. Over a long time interval, the fluctuations largely average out leaving a relatively small mean value. These long-term current effects are illustrated in Figures 7 and 8 . In Figure 7 , the predicted $x$ and $y$ drift rates for each station with and without geostrophic currents and tilt have been integrated over a $720 \mathrm{~d}$ period and compared with the observed final position. In Figure 8 , the predicted drift rate for the center of the triangle formed by the three stations was integrated over $60 \mathrm{~d}$ intervals and compared to the observed drift. Part $\mathrm{b}$ of this figure shows the low 
viscosity or free-drift result for the same situation. Overall the geostrophic currents account for about $30 \%$ of the drift, with the direction being generally toward the GreenlandSpitsbergen passage, while tilt alone accounts for perhaps $15 \%$ of the cumulative effect and has an average direction essentially parallel to the Canadian Archipelago.

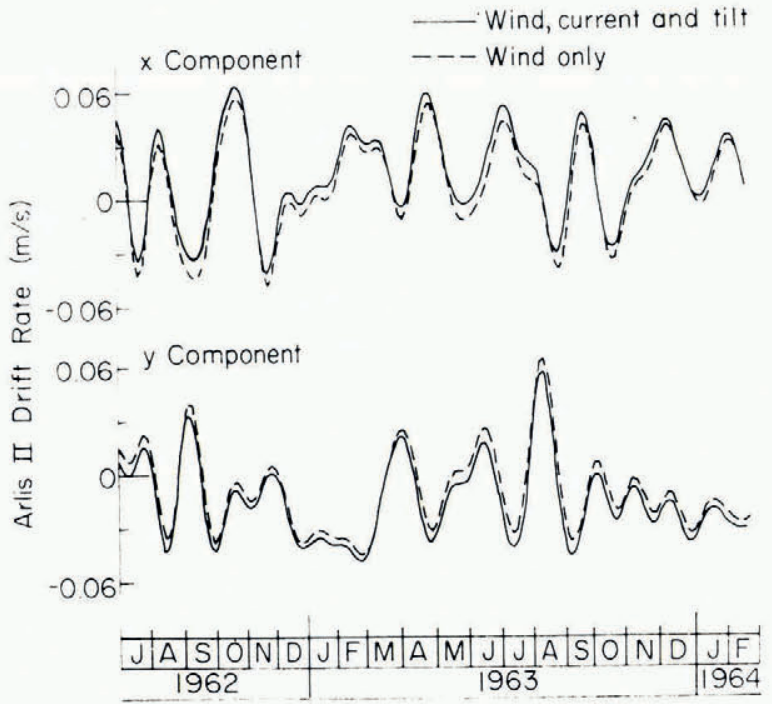

Fig. 6. Effect of currents and tilt on the 25 d smoothed predicted drift-rate of the Arlis II ice island.

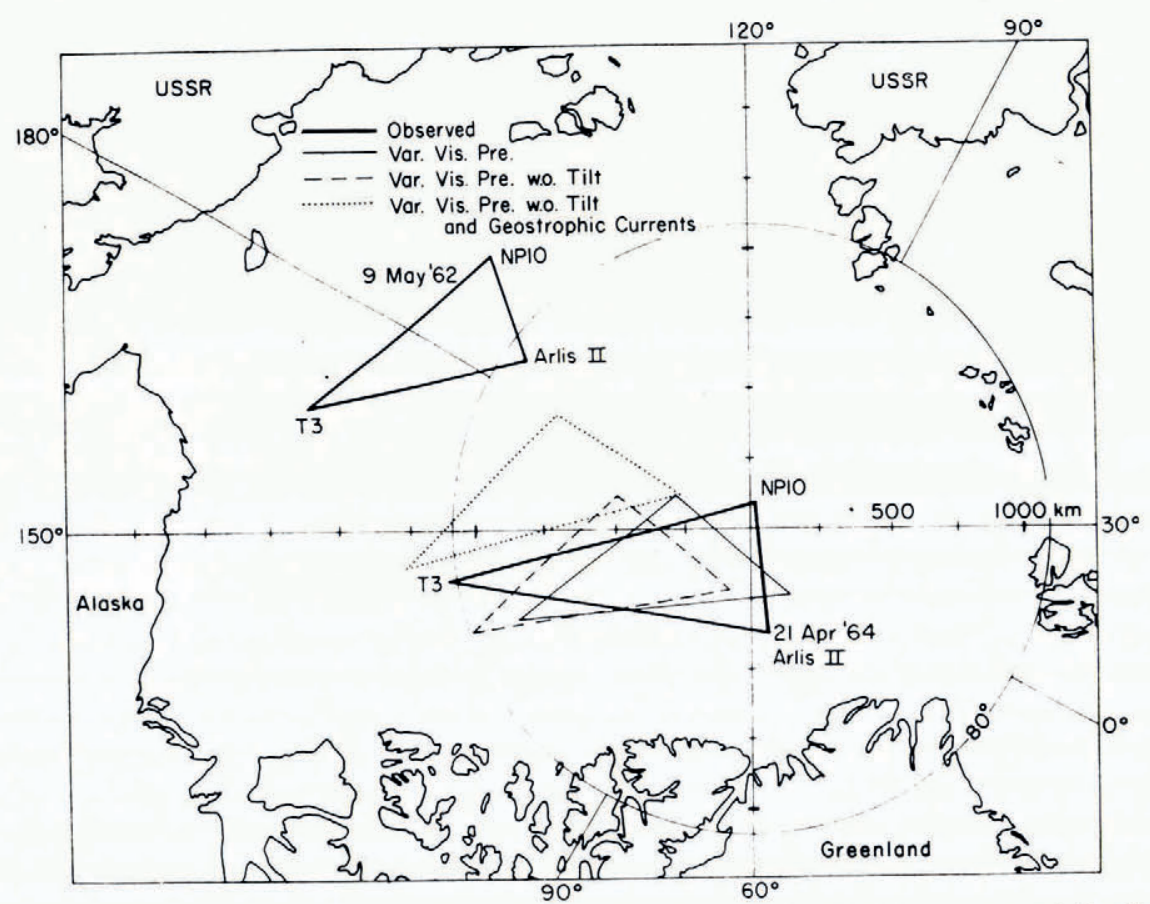

Fig. 7. Predicted and observed net drift of the three drifting stations with and without current and tilt effects. 


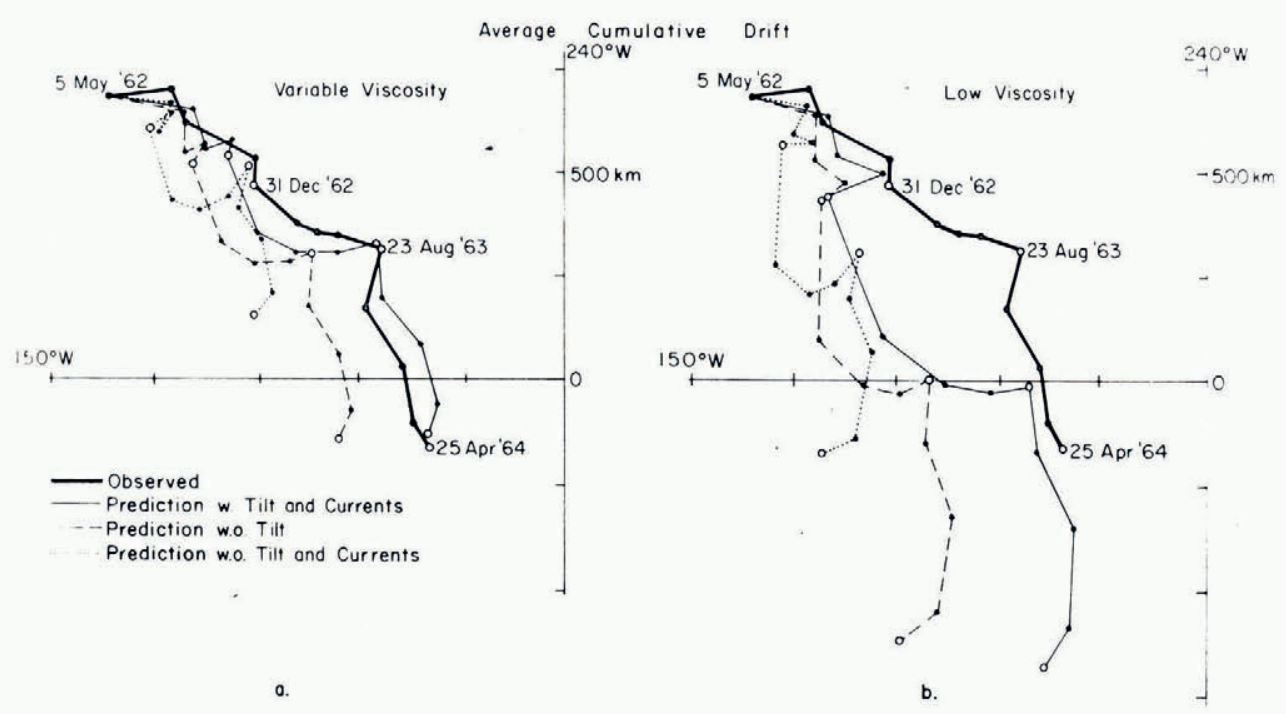

Fig. 8. Predicted and observed three-station average drift integrated over 60 d intervals.

\section{Conclusions}

The primary objective of this paper was to simulate the effects of ice stress on sea-ice drift empirically by using a linear-viscous model. Secondary goals were to examine the sensitivity of the ice drift to ocean currents and the magnitude of the wind stress. For this purpose a series of calculations were carried out using idealized periodic boundary conditions.

The results from these calculations indicate that sea-ice movement in the central Arctic Ocean can be simulated by a linear-viscous constitutive law and a seasonally varying viscosity. The low ratio of ice velocity to wind stress seen in winter is effected in the model by a high viscosity. The viscous model also naturally modifies the turning angle between the local wind and ice motion in agreement with observation. In summer, the viscosity is low enough that the model reduces nearly to one of free drift. The viscosity was found to correlate well with the growth rate of $50 \mathrm{~cm}$ ice, reflecting the physical notion that rapid growth of thin ice in winter will cause thin ice to be less abundant, and the ice cover to be stronger. Steady currents have a negligible effect on short-term drift (weeks) but are important to the long-term drift (years).

The same success in simulation could probably be achieved with a free-drift model with seasonally varying drag coefficients and turning angles. However, the viscous model has the advantage of treating ice stress directly as a term in the momentum equation. It remains to be seen whether non-linear viscous or plastic models can provide better simulations.

\section{AcKnowledgements}

We wish to thank Dr W. F. Weeks and Mr S. F. Ackley of U.S. Army CRREL for valuable discussions and comments on this work. Comments by an anonymous reference also helped clarify a number of points and improved the final paper. Drift-station data were kindly provided by Dr Alan Thorndike at the University of Washington. This research was supported by the Office of Naval Research and through Geophysical Fluid Dynamics Laboratory/ NOAA Grant Number 04-3-022-33.

MS. received 20 May 1977 and in revised form 9 May 1978 


\section{REFERENCES}

Campbell, W. J. 1965. The wind-driven circulation of ice and water in a polar ocean. Fournal of Geophysical Research, Vol. 70, No. 14, p. 3279-301.

Coachman, L. K., and Aagaard, K. 1974. Physical oceanography of Arctic and subarctic seas. (In Herman, Y., ed. Marine geology and oceanography of the Arctic seas. Berlin, etc., Springer-Verlag, p. 1-72.)

Coon, M. D., and others. I974. Modelling the pack ice as an elastic-plastic material, by M. D. Coon, G. A. Maykut, R. S. Pritchard, D. A. Rothrock. and A. S. Thorndike. AIDJEX Bulletin, No. 24, p. 1-106.

Davis, T. M., and Kontis, A. L. 1970. Spline interpolation algorithms for track-type survey data with application to the computation of mean gravity anomalies. U.S. Naval Oceanographic Office. Technical Report No. 226.

Doronin, Yu. P. 1970. K metodike rascheta splochennosti i dreyfa l'dov [On a method of calculating the compactness and drift of ice floes|. Trudy Arkticheskogo i Antarkticheskogo Nauchno-Issledovatel'skogo Instituta, Tom 291 , p. 517. [English translation in AID JEX Bulletin, No. 3, 1971, p. 22-39.]

Glen, J. W. 1970. Thoughts on a viscous model for sea ice. AIDFEX Bulletin, No. 2, p. 18-27.

Hibler, W. D., III. 1974. Differential sea-ice drift. II. Comparison of mesoscale strain measurements to linear drift theory predictions. Fournal of Glaciology, Vol. 13, No. 69, p. 457-71.

Hibler, W. D., III. 1977. A viscous sea ice law as a stochastic average of plasticity. Journal of Geophysical Research, Vol. 82 , No. 27 , p. $3932-38$.

Hibler, W. D., III. In press. A dynamic thermodynamic sea ice model. Journal of Physical Oceanography, Vol. 9 .

Hibler, W. D., III, and Tucker, W. B., III. 1977. An examination of the viscous wind driven circulation of the Arctic ice cover over a two year period. AID JEX Bulletin, No. 37, p. 95-1 34 .

Rothrock, D. A. 1975. The steady drift of an incompressible Arctic ice cover. Journal of Geophysical Research, Vol. 8o, No. 3, p. $387-97$.

Thorndike, A. S., and others. 1975. The thickness distribution of sea ice, [by] A. S. Thorndike, D. A. Rothrock, G. A. Maykut, and R. Colony. Journal of Geophysical Research, Vol. 80, No. 33, p. 4501-13. 